\title{
Sustainability Transition: Quest for a New Social Contract
}

This chapter will provide an overview of the necessity and nature of the sustainability transition, starting with the paradox of prosperity (Sect. 2.1), the ecological boundaries of our planet (Sect. 2.2) and how this relates to a broad range of security and justice issues (Sect. 2.3). Following this, the chapter provides a brief description of the nature of the sustainability transition (Sect. 2.4), and concludes with an argumentation to be more explicit on what comes after the Sustainable Development Goals (SDGs) of the UN 2030 Agenda (Sect. 2.5).

\subsection{Paradox of Prosperity}

Economies around the world are usually designed for one purpose: economic growth. In recent decades, the free market has flourished, and though it has brought tremendous economic prosperity to society in the process, it also has major downsides. The positive prospects for globalization and economic growth that spurred people on in the 1990s have made way for uncertainty, an actual crisis (the 2008 global credit crisis), and fears about the future. Already in 2006 the Stern Review on the Economics of Climate Change concluded that: 'Our actions over the coming few decades could create risks of major disruption to economic and social activity, later in this century and in the next, on a scale similar to those associated with the great wars and economic depression of the first half of the twentieth century' (Stern Review 2006, page xv).

Never before has humankind been confronted with the negative consequences of its own actions on such a large scale. Growing wealth inequality, depletion of natural resources, pollution of water, land, and air, climate change, loss of biodiversity, malnutrition, and (often within one country) diseases of affluence such as obesity and diabetes type II, financial crises (in 2008 and 2020), epidemics and pandemics (including Avian Flu, SARS, MERS, Corona-virus), trade wars (e.g. between the USA and China), and migration challenges (e.g. Syria, and climate change-related refugees in many parts of the world) are but some of the issues we face today. We are 
now discovering that the ecological vulnerability translates into social and economic vulnerability. These problems feed fear, powerlessness, and uncertainty about developments that individuals do not seem to be able to control. Accordingly, the downside of prosperity has major consequences for society and the planet. This is also known as the paradox of prosperity. I will follow-up on the economic debate behind this paradox in Chap. 3 .

By way of illustration, recent research has shown the increase in economic capital in the Netherlands has been out of step with the country's 'broad prosperity' since the 1970s (Lintsen et al. 2018). Broad prosperity includes the economic, ecological, and social aspects of prosperity, such as education, health, good governance, social equality, the quality of the environment, and natural capital. The Broad Prosperity Monitor (CBS 2020) paints a troubling picture of the trend of broad prosperity in the Netherlands (see Fig. 2.1), with indicators related to natural capital steadily declining or not improving. Also trends in human and social capital are out of step with the increase in economic capital. The report shows that using economic growth as a compass for government policy could, in the long run, have disastrous consequences (Lintsen et al. 2018).

The Broad Prosperity Monitor also looks at broad prosperity elsewhere, i.e. the effects that Dutch society has on the rest of the world. Again, the results are worrying. The trends in this area show that the Netherlands has started using more and more fossil fuels and biomass originating from the rest of the world, the least developed countries in particular (CBS 2018, 2020). In many African countries in particular, this trade in natural resources leads to problems that can reduce broad prosperity in those countries, and often mainly benefit a small elite; a phenomenon called the 'resource curse' in literature (ibid).

\subsection{Ecological Limits of Our Planet}

The necessity of a Natural Social Contract underlying a sustainable society becomes clear when we look at the ecological boundaries of our planet.

The planet's ability to sustain humankind is put under increasing pressure, primarily due to the growing world population, economic growth, large-scale pollution, depletion of natural resources, and climate change. In order to keep our planet healthy for future generations, we will have to accurately map out and respect our planet's boundaries. This is by no means an easy task. Johan Rockström et al. (2009) have mapped nine of our planet's boundaries: climate change, loss of biodiversity, excess nitrogen and phosphorus production, stratospheric ozone deposition, ocean acidification, global freshwater consumption, changes in land use caused by agriculture, air pollution, and chemical pollution.

While three of those boundaries had already been exceeded in 2009, a follow-up study published in Science in 2015 claimed that 4 of the 9 planetary boundaries have already been exceeded as a result of human activity, namely climate change, loss of biosphere integrity (in 2009 called: loss of biodiversity), changes in land use caused 


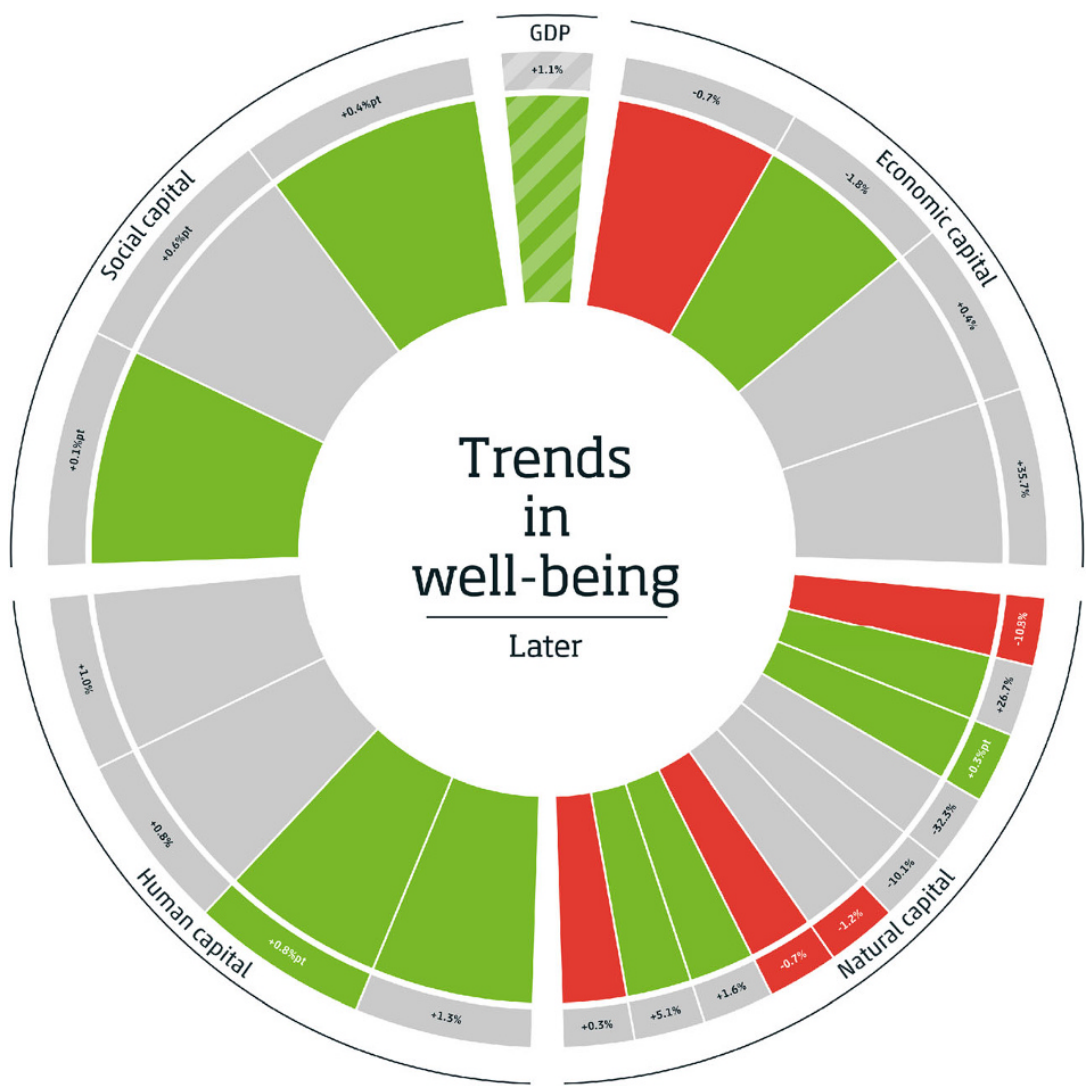

Key

Medium-term trend (8 years)

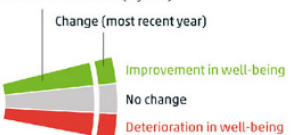

EU ranking

The bars show the

Netherlands' ranking

in the European Unio

for each indicator.

\section{Key}

- High ranking

- Middle ranking

- Low ranking

O No data
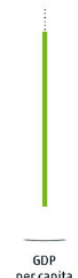

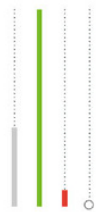

01020304

Economic

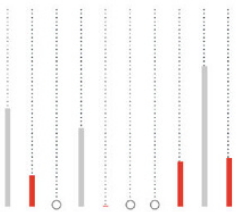

$05 \quad 06 \quad 07 \quad 08 \quad 091011$

Natural capital

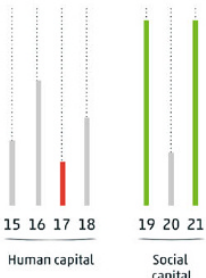

01 Physical capital stock / 02 Knowledge capital stock / 03 Average household debt / 04 Median wealth of households / 05 Fossil energy reserves / 06 Renewable electricity capacity / 07 Managed natural assets within NNN / 08 Phosphorus surplus / 09 Nitrogen surplus / 10 Fauna on land / 11 Fauna in freshwater and marshes /

12 Surface and ground water abstraction / 13 urban exposure to particulate matter $\left(\mathrm{PM}_{2}\right) / 14$ Cumulative $\mathrm{CO}$, emissions / 15 Hours worked / 16 Higher educated population /

17 Healthy life expectancy of women / 18 Healthy life expectancy of men / 19 Trust in other people / 20 Feelings of discrimination / 21 Trust in institutions

Fig. 2.1 Broad Well-being Trends (Central Bureau of Statistics 2020) 


\section{Planetary Boundaries}

A safe operating space for humanity

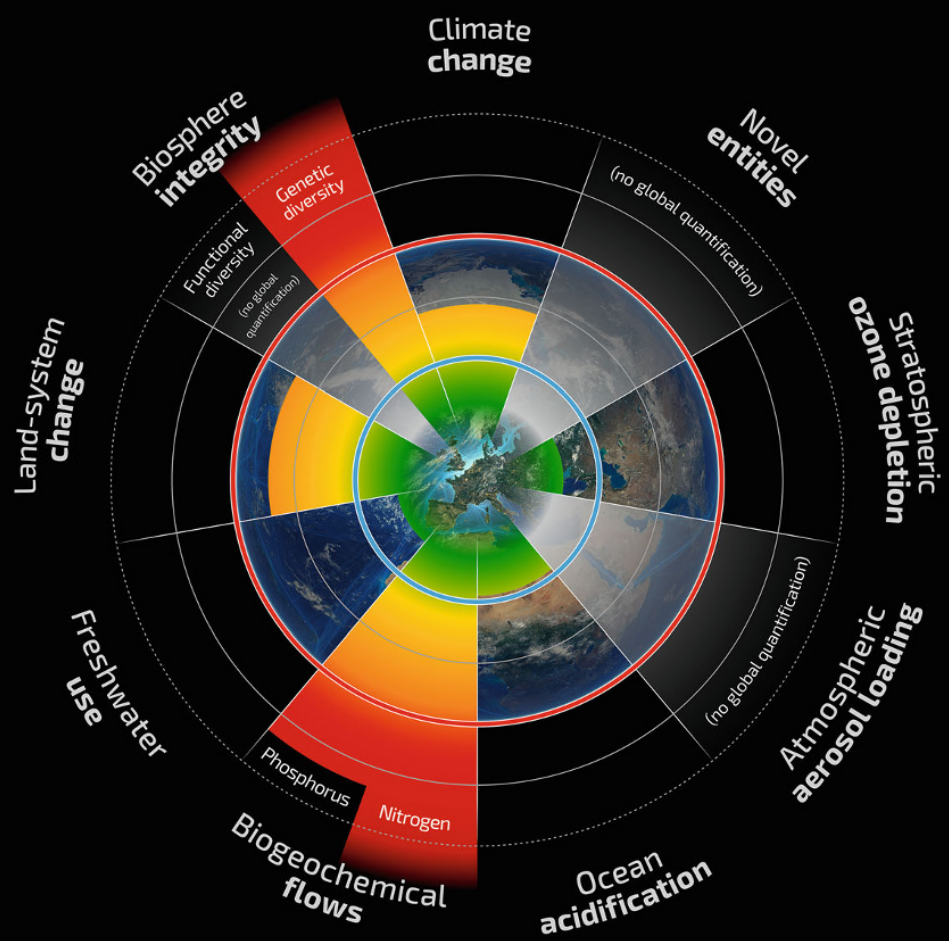

Beyond zone of uncertainty (high risk)

In zone of uncertainty (increasing risk)

Below boundary (safe)

Boundary not yet quantified

Fig. 2.2 Boundaries for nine planetary systems (Steffen et al. 2015). The wedges represent an estimate of the current status of each variable

by agriculture, and excess nitrogen and phosphorus production (Steffen et al. 2015). See Fig. 2.2.

Humankind has triggered a biodiversity crisis that is no less severe than the climate crisis. A report of the UN biodiversity panel (IPBES 2019) shows that without rapid, far-reaching measures, hundreds of thousands of plant and animal 
species will become extinct and vital ecosystems will decline. 'The liveability of our planet is at risk', so concludes the UN report on biodiversity (IPBES 2019). Loss of biodiversity is at least as great a threat to humankind as global warming, but the UN is concerned that the urgency of halting declining biodiversity and ecosystems is much less keenly felt. This, however, is at our own peril, the UN report concludes, because the decline is a direct consequence of our consumption patterns and nature and biodiversity are essential for food production, our water supply, medicine supply, and general public safety and social cohesion (ibid.).

The 1800-page UN report paints a gloomy picture of the many ways in which humankind is plundering nature and undermining its ecosystem services (the benefits that living nature confers on humankind). More than $75 \%$ of all land, $40 \%$ of the oceans, and $50 \%$ of our rivers have been degraded due to deforestation for agricultural and livestock farming purposes, by mining, urbanization, infrastructure, and fishing. Only $13 \%$ of all land and $23 \%$ of the oceans are still more or less untouched. More than 20\% of all agricultural land is degraded (IPBES 2019).

Ecosystem pollution also takes its toll. For example, more than $80 \%$ of the world's wastewater is not treated. In addition, an estimated 300 to 400 million tonnes of heavy metals and other toxic substances are dumped into the environment, as a result of which $40 \%$ of the world's population does not have access to clean drinking water, to name but one consequence. Millions of tonnes of plastic disappear into the oceans every year (ibid.).

Nature and biodiversity are essential in our fight against climate change. Forests and oceans absorb half of our carbon emissions. Over the past 5 years, however, deforestation has wiped out rainforest equivalent to five times the size of England for agriculture in order to meet the world's needs for beef, soybeans, palm oil, and biofuels (ibid.).

'Climate change has been called the single biggest challenge for humanity over the coming centuries (UNSG 2014, 2018; McKibben 2019). Given the scale of the problem, its impacts on human life, and the level of coordinated action required to address it, this statement seems more than justified. After the Intergovernmental Panel for Climate Change (IPCC) published its first assessment report in 1990 it was accused of dramatizing the anthropogenic causes as well as the potential effects of global warming; now we know that the researchers had in fact underestimated both causes and effects. Although uncertainty and unpredictability remain, the scientific basis of climate change is now well established. It suggests that change is happening more quickly than previously estimated and can no longer be framed as a distant threat (Stern 2013). The past three decades have likely been the warmest 30 years of the last 1400 years (IPCC 2013). The atmospheric concentration of greenhouse gases (GHG) has increased to a level unprecedented in the last 800,000 years, and their "mean rates of increase" over the past century "are, with very high confidence, unprecedented in the last 22,000 years" (idem). Changing precipitation patterns, melting ice caps, rising sea levels, acidification of oceans, and heightened climatic variability are only some of the predictable consequences of a climate destabilized by warming atmosphere and oceans' (cf. Huntjens and Nachbar 2015; Huntjens et al. 2018). 
In October 2018, the United Nations Intergovernmental Panel on Climate Change (IPCC) published a landmark report that concluded that governments must take urgent, unprecedented, and far-reaching action by 2030 in order to limit global warming to a maximum of 1.5 degrees Celsius. However, the target set in the Paris climate agreement of a maximum of 1.5 degrees of warming will almost certainly not be achieved, such is the painful conclusion of the UN climate panel (IPCC 2018).

Recent information from the World Meteorological Organization, the World Bank, and the International Energy Agency shows the relentless pace of climate change (WMO 2019).

With global warming, we are now seeing deadly heat waves and massive wildfires in some parts of the world, while the largest physical structures on our planet, such as coral reefs, ice caps, and rainforests, disappear before our eyes (McKibben 2019). António Guterres, the United Nations secretary general, said, 'I am beginning to wonder how many more alarm bells must go off before the world rises to the challenge' (UNSG 2018).

The UN climate panel notes that global warming is currently more likely to reach 3 degrees than 2, let alone the targeted 1.5 degrees. This is because the 195 countries that signed the Paris Climate Agreement have not yet devoted enough effort to reducing their greenhouse gas emissions. As of 2018, global carbon emissions amount to some 42 billion tonnes. If we keep going at the current rate, we will have reached 1.5 degrees of warming in about 15 years from now (IPCC 2018).

Based on the above, we can undoubtedly state that humankind has wreaked havoc on the planet. 'Our planet is ill, and the disease is called man'. This is the diagnosis made by Friedrich Nietzsche, one of the brightest philosophers in European history, some 150 years ago. As a species, humans can be compared to a parasitic infectious disease that kills its own host, i.e. our planet. This image stands in stark contrast to the common belief that humankind is the highest, most developed species in nature. The great existential question of our time is whether humankind can shift from being a parasitoid to a symbiotic species that can live sustainably with its host, i.e. planet earth, on time. The answer to that question is an emphatic YES, provided that people as individuals, groups, and societies, from global to local, are willing to immediately and effectively make work of the sustainability transition.

There is every reason to unite our efforts and work on this issue together. Humankind is the only species on this earth that-based on scientific insights, public debate, and collective action-can deliberately steer its behaviour. This means society has enormous potential for technological and societal innovation and adaptability.

\subsection{Emerging Security and Justice Challenges}

Security and justice mean different things to different groups and individuals and the potential implications of climate change, resource depletion, and environmental degradation for security and justice are varied and complex (Huntjens et al. 2018). 
Both the security and justice implications of climatic change and environmental degradation have been subject to an increasingly broad debate in the scientific as well as the policy community. Despite this increase in attention, the ways in which the effects of the ecological crisis will impact security and justice at various levels are still far from clear (ibid.).

'Human security as a concept aims to capture the broad range of factors that determine people's livelihoods and their ability to exercise their human rights and fulfil their potential. The UNDP's 1994 Human Development Report definition argues that the scope of global security should be expanded to include threats in seven areas: economic, food, health, environmental, personal, community and political security (UNDP 2011). For instance, climate change is understood as a threat to human security in that it disrupts individuals' and communities' capacity to adapt to changing conditions, usually by multiplying existing or creating new strains on human livelihoods (Brauch and Scheffran 2012; Barnett and Adger 2007). The various effects of global warming, resource depletion, and environmental degradation are already being felt as real consequences for real people and communities around the world. Because it changes ecosystems that form the basis not just for plant and animal but human life, climate change is a development that goes to the very heart of human coexistence and confronts us with challenges concerning the security as well as justice of our societies' (cf. Huntjens and Nachbar 2015; Huntjens et al. 2018).

The human security approach emphasizes 'the interconnectedness of both insecurities and responses. Insecurities are interlinked in a domino effect in the sense that each insecurity feeds on the other. If not managed proactively, these can spread to other regions or countries. For example, climate change may induce drought, giving rise to food insecurity with impacts on health, while competition over scarce resources threatens community cohesion, and personal and political security' (cf. United Nations 2016). Besides human security, other security dimensions such as planetary security, as well as national security and international security (the security of states) need to be taken into account. An overview of security challenges is provided in Table 2.1 .

'A broad range of human rights is affected by climate change and environmental degradation, including the rights to life, freedom of movement, housing, water, food, health or professional development. Consequently, they ought to be dealt with in national and international human rights bodies, such as the European Court of Human Rights, the European Parliament subcommittee on human rights, the Council of Ministries at the Council of Europe and during UN Human Rights Council Sessions. A human rights-centred approach shifts the focus from purely economic and scientific considerations and consequences towards human rights violations caused or exacerbated by climate change or environmental degradation. This approach enhances democratization through active citizen participation and the claim for transparency and accountability. Thus, a positive side-effect of such responses to climate change is the creation of new ways of governance seeking justice based on good governance principles' (cf. Huntjens et al. 2018). 
Table 2.1 Security challenges (non-exhaustive) related to the various effects of global warming, resource depletion, and environmental degradation

\begin{tabular}{|c|c|}
\hline Security challenge & Brief explanation \\
\hline Planetary security & $\begin{array}{l}\text { Four planetary boundaries have already been exceeded as a result } \\
\text { of human activity, namely climate change, loss of biodiversity, } \\
\text { changes in land use caused by agriculture and excess nitrogen } \\
\text { and phosphorus production (Steffen et al. 2015). }\end{array}$ \\
\hline Food security & $\begin{array}{l}\text { Over the coming decades, a changing climate, growing global } \\
\text { population, rising food prices, and environmental stressors will } \\
\text { have significant yet uncertain impacts on food security. } \\
\text { Currently, about } 2 \text { billion people in the world experience } \\
\text { moderate or severe food insecurity (FAO, IFAD, UNICEF, WFP, } \\
\text { and WHO, 2019). The lack of regular access to nutritious and } \\
\text { sufficient food that these people experience puts them at greater } \\
\text { risk of malnutrition and poor health. Although primarily } \\
\text { concentrated in low- and middle-income countries, moderate or } \\
\text { severe food insecurity also affects } 8 \text { percent of the population in } \\
\text { Northern America and Europe (ibid.). }\end{array}$ \\
\hline Water security & $\begin{array}{l}\text { 'There are many factors affecting water security, including a } \\
\text { growing population, agricultural irrigation, rising domestic } \\
\text { demand due to rising standard of living, increasing industrial } \\
\text { demand, escalating energy consumption, mining, climate } \\
\text { change, urbanization, deforestation, and migration of people' } \\
\text { (cf. Singh 2017). Water Security is defined by UN-Water (2013) } \\
\text { as 'The capacity of a population to safeguard sustainable access } \\
\text { to adequate quantities of acceptable quality water for sustaining } \\
\text { livelihoods, human well-being, and socio-economic } \\
\text { development, for ensuring protection against water-borne } \\
\text { pollution and water-related disasters, and for preserving } \\
\text { ecosystems in a climate of peace and political stability'. For more } \\
\text { on water security see Pahl-Wostl et al. (2016) }\end{array}$ \\
\hline Energy security & $\begin{array}{l}\text { Climate change tends to negatively affect the power sector, inter } \\
\text { alia, by causing cooling problems in power plants and impairing } \\
\text { the water supply required for hydropower generation (Van Vliet } \\
\text { et al. 2013; Rübbelke and Vögele 2013). }\end{array}$ \\
\hline Economic security & $\begin{array}{l}\text { According to the Global Risk Report (World Economic Forum } \\
\text { 2020) the top five of risks to global economy (in terms of } \\
\text { likelihood) are: (1) Extreme weather, (2) Climate action failure, } \\
\text { (3) Natural disasters, (4) Biodiversity loss, and (5) Human-made } \\
\text { environmental disasters. From a business perspective, climate } \\
\text { change poses wide-ranging threats to business operations, such } \\
\text { as reduction/disruption in production capacity and supply chains, } \\
\text { increased operational costs, or inability to do business, with the } \\
\text { latter usually resulting in loss of jobs. }\end{array}$ \\
\hline Environmental security & $\begin{array}{l}\text { 'Environmental security is the proactive minimization of } \\
\text { anthropogenic threats to the functional integrity of the biosphere } \\
\text { and thus to its interdependent human component' (cf. Barnett } \\
\text { 1997). There multiple threats to environmental security, such as } \\
\text { resource scarcity (diminishing supplies of inputs into human } \\
\text { systems) and pollution (the contamination of inputs into human } \\
\text { systems), occurring at multiple scales (from global to local). } \\
\text { (Barnett 2009). 'The condition of environmental security is one }\end{array}$ \\
\hline
\end{tabular}


Table 2.1 (continued)

\begin{tabular}{|c|c|}
\hline Security challenge & Brief explanation \\
\hline & $\begin{array}{l}\text { in which social systems interact with ecological systems in } \\
\text { sustainable ways, all individuals have fair and reasonable access } \\
\text { to environmental goods, and mechanisms exist to address } \\
\text { environmental crises and conflicts' (cf. Glenn et al. 1998). }\end{array}$ \\
\hline Health security & $\begin{array}{l}\text { Environmental degradation can have a significant impact on } \\
\text { human health. 'Air pollution and exposure to hazardous } \\
\text { chemicals are important causes of the environment-related } \\
\text { burden of disease in OECD countries' (cf. OECD 2011). 'The } \\
\text { transport and energy sectors are major contributors to air } \\
\text { pollution, while important sources of chemical pollution are } \\
\text { agriculture, industry, and waste disposal and incineration' } \\
\text { (cf. ibid.). Furthermore, health security is threatened by } \\
\text { environmental stressors such as malnutrition and insufficient } \\
\text { access to health services, clean water, and other basic necessities. }\end{array}$ \\
\hline $\begin{array}{l}\text { Community, personal and } \\
\text { political security }\end{array}$ & $\begin{array}{l}\text { 'Competition over scarce resources threatens community } \\
\text { cohesion, and personal and political security (United Nations } \\
\text { 2016). The effects of climate change, particularly climate change } \\
\text { related environmental impacts and associated resource scarcity, } \\
\text { and following migration of people once coupled with other } \\
\text { structural and socio-political factors can contribute to exacerbate } \\
\text { existing conflicting relations between parties in destination area' } \\
\text { (cf. Islam and Nur 2019). } \\
\text { In addition, 'rapid onset events (such as storms, floods, and bush } \\
\text { fires) and slow onset events (such as droughts, water scarcity, sea } \\
\text { level rise, desertification, and coastal erosion) place stress on } \\
\text { those who are already vulnerable, such as indigenous peoples, } \\
\text { women, and children. These groups may be more dependent on } \\
\text { natural resources and a healthy ecosystem for their survival and, } \\
\text { in addition, may have less access to coping mechanisms } \\
\text { (e.g. mobility, land ownership, and emergency funds) in their } \\
\text { place of residence. As a result, they become refugees, migrants, } \\
\text { or Internally Displaced Persons (IDPs) as an adaptation strategy' } \\
\text { (cf. Huntjens et al. 2018). Since 2008, an average of nearly } \\
\text { twenty-seven million people have been displaced annually by } \\
\text { natural hazard-related disasters. This is the equivalent to one } \\
\text { person being displaced every second (IDMC 2015). The effects } \\
\text { of climate change are expected to intensify such disasters and } \\
\text { accelerate displacement rates in upcoming decades (ibid.). }\end{array}$ \\
\hline $\begin{array}{l}\text { National and international } \\
\text { security }\end{array}$ & $\begin{array}{l}\text { Climate change is a threat to national and international security } \\
\text { (the security of states) in two ways. Firstly, climate change } \\
\text { contributes to higher instability in some of the world's most } \\
\text { volatile regions. Secondly, climate change can contribute to } \\
\text { tensions in stable regions (CNA Military Advisory Board 2007; } \\
\text { Huntjens et al. 2018). Most strategic documents that have } \\
\text { established a link between climate change and state security have } \\
\text { also emphasized the need for disaster preparedness and measures } \\
\text { aimed at building resilience in countries at risk of climate- } \\
\text { induced conflict (Brzoska 2012) }\end{array}$ \\
\hline
\end{tabular}


'A range of immediate and effective mechanisms is needed to safeguard the rights of future generations and protect them from the potential negative implications and harm caused by climate change and environmental degradation. Polly Higgins and colleagues argue that the rights of nature itself must be protected against ecocide (Higgins 2010; Gauger et al. 2012; Higgins et al. 2013; Lay et al. 2015), and propose to criminalize human activities that cause extensive damage to ecosystems. One proposed step forward could be the legal acknowledgement of the crime of ecocide as the fifth Crime Against Peace, the other four being genocide, crimes against humanity, war crimes, and the crime of aggression as set out in the Rome Statute of the International Criminal Court. The United Nations has discussed the crime of ecocide for decades (see Gauger et al. 2012), although the chances of succeeding in modifying the Rome Statue are small, particularly as countries with large fossil fuel interests or with large fossil fuel related multinationals are likely to vote against, afraid of being held accountable and combined with a complex set of legal complications' (cf. Huntjens and Zhang 2016).

In contrast to international law, a more effective approach, so far, is illustrated 'by a variety of lawsuits on climate change and environmental degradation in national jurisdictions, while several states have started to recognize the rights of nature, ecosystems, and animals and there has been an increasing recognition of the intersection between human rights and environmental degradation' (cf. Huntjens et al. 2018). Significantly, several court judgements afford protection to ecosystems and animals (ibid.), while several countries have recognized Rights of Nature in their legal frameworks and/or jurisprudence, e.g. in Uganda, Peru, Ecuador, Mexico, Colombia, India, Bangladesh, New Zealand, and communities in the USA.

More recently, lawsuits to force countries towards an effective climate policy are increasingly being considered as an important avenue for breaking through political indifference and deadlock (ibid.). The verdict in the court case on climate justice in the Netherlands is the first of its kind worldwide. When filing the court case, civil society organization Urgenda argued that the government is doing too little and should be held accountable for not taking appropriate action to safeguard a healthy environment for future generations. In particular, Urgenda claimed that the Netherlands must reduce greenhouse gases drastically by 2020, and much more than agreed to within the EU. In its defence the State of the Netherlands made an appeal to EU policies and international agreements. In addition, the State relied on the separation of powers: it claimed that political decisions on climate policy should not be taken in court, but by the government and parliament. The judge argued that independent courts sometimes need to decide on the conduct of politics, but it must be done with reticence. Since mitigation of climate change actually requires a reduction of 25 to 40 percent of GHG in 2020, with explicit reference to scientific consensus on this topic, the judge found 25 percent a modest and thus reticent requirement, when compared to the upper target of 40 percent. As a result, the State of the Netherlands was legally forced to reduce greenhouse gas emissions with at least $25 \%$ by 2020 , much more than its own government plans, which was about $17 \%$ by the time of filing the court case. Never before has a court sentenced a national government to a more effective climate policy. 
While it is important to recognize the progress made by national jurisdictions in addressing crimes to the environment, a void within international law remains and affects the ability of domestic jurisdictions to respond to grave problems of climate change. For instance, 'the Arctic is still protected by soft law instruments only, and the legal regime protecting the environment against reckless exploitation remains inadequate' (cf. Lay et al. 2015).

\subsection{The Sustainability Transition: Humankind's Quest for a New Social Contract}

The five decades from 2000 to 2050 will go down in history as the sustainability transition. The sustainability transition constitutes a search for a new social contract, in this book coined as a Natural Social Contract (see Chap. 3). The core philosophy behind a social contract is that the members of a society enter into an implicit contract with the goal of living a better, safe life together (Kalshoven and Zonderland 2017). Such a contract includes agreements about public goods and services, for instance, as well as taxes, detailing how everyone contributes to and benefits from society. The purpose of the social contract is serving the common or greater good to ensure the sustainability of the society in question and protect the individuals within it. In other words, the social contract is expected to provide security and justice for all (see Sect. 3.1 for more details).

The global and systematic nature of the environmental problems we face today necessitates fundamental changes in key societal, economic, and legal systems. Making these changes, however, will require much more than step-by-step efficiency improvements. Rather, we will have to realize profound, long-term changes in dominant practices, policies, and philosophies that, in turn, will require new knowledge.

Transition is defined as a fundamental change in the structure (institutional, physical, and economic structure), culture (shared ideas, values, and paradigms), and methods (routines, rules, behaviour) of a system (Rotmans 2005). The sustainability transition will have to include changes in all these dimensions if we are to leave the earth in better shape for future generations. This also means overcoming short-termism and a singular focus on economic growth, which currently dominate political and economic thought. On the flip side, the list with counter-proposals to unlimited economic growth has grown rapidly and the rollout is getting stronger, in particular since the 2008 global credit crisis (see Sect. 3.2). The Corona-crisis is expected to become the next major tipping point towards a sustainable society, illustrated by an observation from EU-officials that the new EU Green Deal is expected to have an accelerated implementation due to the devastating impact of the Corona-crisis on industries relying on burning fossil fuels, such as the car and aviation industry, transportation, agriculture, construction, and electricity production. In any case, the granting of substantial EU aid packages to keep the economy going during the Corona-crisis will have to go hand in hand with hard conditions for a transformation towards a green economy, according to the EU. 
The call for fundamental societal changes targeting sustainability is high on local, national, and international agendas. At the global level, the United Nations have set Sustainable Development Goals, as part of its 2030 Agenda, comprising both socioeconomic and environmental dimensions of sustainability. In Europe, 'a good and healthy life in 2050 within our planet's ecological boundary' is a core component of environmental policy (EU, 7th Environment Action Programme 2013). This vision has also been incorporated in other lines of EU policy.

In the past two decades, the European Union has introduced a large body of environmental legislation, which has succeeded in significantly reducing air, water, and soil pollution. Legislation on chemicals has been modernized and the use of many toxic or hazardous substances has been restricted. Today, EU citizens boast the highest-quality water in the world, and more than $18 \%$ of the land mass covered by the EU has been designated as a protected area. However, many problems remain and must be tackled in a structured way (EU, 7th Environment Action Programme 2013). To solve these problems and achieve the goals set in environmental policy, the EU will need to make far-reaching changes in its production and consumption systems. The Low-Carbon Economy Roadmap, for instance, aims to reduce greenhouse gas emissions in the EU by $80 \%$ by 2050 , while the Circular Economy Strategy focuses on significant improvements in waste reduction and management by 2030. In December 2019, 'the European Commission released the European Green Deal, a blockbuster policy aimed at halting climate change by shifting to clean energy and a circular economy, thereby increasing resource efficiency and restoring biodiversity. The agreement will establish a €100bn "Just Transition Mechanism" and urge European countries to set up a broad national tax reform Mechanism, with "climate taxes" as the focus' (cf. UN-Habitat 2020).

Within the sustainability transition, we can identify three important systemic changes:

1. climate and energy: greenhouse gas emissions (such as carbon dioxide, methane, and nitrous oxide) must be reduced drastically. Fossil energy must be replaced en masse by clean energy. Climate change mitigation and adaptation is required in almost every sector.

2. agriculture and food: the quality of nature, water, and air must be improved without compromising the production of a sufficient supply of healthy, sustainable, and safe food. All around the world, we will have to feed approximately 10 billion mouths by 2050 .

3. circular and regenerative economies and cultures: the depletion of raw materials and the continued undermining of ecosystems must be prevented.

This transition to a new, sustainable economy and society has many faces. The next economy will be a digital, bio-based, circular, sharing, maker and robot economy (RNE 2016). The new economy will be increasingly based on horizontal relationships and small-scale, locally organized networks of producers and consumers rather than vertically integrated structures (ibid.), but the new economy will also be characterized by great uncertainty and disruptive developments (ibid.). 
Many traditional sectors, such as the fossil fuel industry and companies that fail to make serious work of sustainability, may disappear. On the other hand, new sectors will emerge, including the sector for renewable energy and circular economy, creating new jobs.

The Netherlands government has developed and is still developing a wide range of policies, rules, and regulations to facilitate this transition, such as the National Climate Agreement, a major societal transition that aims to cut carbon emissions in the Netherlands in half by 2030. Another example is the policy vision on Circular Agriculture (LNV 2018), which presents a shared foundation for a societal transition towards circular agriculture and involves addressing agriculture, food (production and consumption), water, nature, climate, and the living environment in a series of concerted efforts. The question is, however, whether this vision will engender a true and radical transition or just several minor changes and efficiency improvements in the existing system. One of the more fundamental questions is whether a policy targeted at circular agriculture is compatible with the promotion of free trade in WTO and GATT negotiations and other fora, in particular by the European Union, the USA, and Japan, while at the same time practicing protectionism and subsidies for the domestic agricultural sector (Otero et al. 2013).

When it comes to radically new practices, insights, and values, however, small steps can resonate, ultimately bringing about large-scale changes (Bryson 1988). That is why, in response to the policy vision on Circular Agriculture (LNV 2018), Termeer (2019) advocates a 'small-wins' approach. This approach aims to work on major societal issues by dividing them into a series of 'small wins': small, meaningful steps with tangible results (Weick 1984; Vermaak 2009). The main thought behind this approach is that it keeps energy levels up and pushes forward progress in the transformation process without resorting to simplistic short-term gains or making impossible promises (Termeer and Dewulf 2017). By focusing on small-scale goals, people are less likely to be overwhelmed by the complexity of a given issue, which would restrict the freedom and precision of their thinking and increase the temptation for abstraction (ibid.). Responding to the 'small-wins' approach, however, Rotmans (2019) and Grin (2019) argue that this approach is too superficial and limited. According to Rotmans (2019), the dynamics of transitions include profound, broad, and slow changes as well as narrow and fast ones, with the essence of the transition being characterized by the 'parallelism of big and small, broad and narrow, fast and slow, construction and demolition'. Grin and Rotmans believe that particularly the transition towards circular agriculture requires system breakthroughs targeting a new culture, a new regime, a new paradigm, and a new infrastructure.

According to the ministry of Agriculture, Nature and Food Quality, the policy vision is not a blueprint for a system of circular agriculture, but rather describes a long-term process during which the government will have to adapt legislation, companies will have to apply circular principles and consumers will have to start paying fairer prices for their food (LNV 2018). Both producers and consumers will have to develop increased awareness and change their behaviour, forming two of the greatest challenges in realizing this agricultural transition. In response to the Ministry's future policy, Rotmans (2019), opposing Termeer (2019), argues that 
the government should not seek to direct matters: 'The harder the government pushes and pulls, the less room it leaves for other parties. Transitions originate from society and economy and though they can be facilitated by the government, this is all the government can do'. This viewpoint is not shared by everyone. A case in point is the historical Urgenda-court case on climate justice (see Sect. 2.3), where the Higher Court concluded, based on scientific evidence, that the Netherlands Government should step up its efforts to reduce greenhouse gases drastically by 2020 .

Reasoning from the perspective of social contract theory (see Chap. 3), and in contrast to above argument of Rotmans (2019), government should do much more than facilitation only. After all, the purpose of the social contract is serving the common or greater good to ensure the sustainability of the society in question and protect the individuals within it. If not, political authority loses its legitimacy, and the social contract will be eroded, or will even fall apart, as illustrated by the Arab spring. Within the context of the sustainability transition, there is a wide variety of policy instruments and policy mixes that can be deployed for making a substantial contribution to the sustainability transition. For example, a systematic review of the European policy ecosystem shows that taxation is the most effective policy tool for mitigating unsustainable and unhealthy products and services in the food system (SAPEA 2020). Tax revenues, in return, can be used to provide positive incentives for realizing a transition to a sustainable and healthy agri-food system.

Many people feel that changing their individual lifestyle will not make a difference. You can put your best foot forward and install solar panels and insulate your house, or eating less meat or no meat at all, but the realization that a selection of only 100 companies is responsible for $71 \%$ of all carbon emissions since 1988 (CDP 2017) could be enough to discourage even the most optimistic mind.

The majority of Dutch citizens (65\%) therefore believe that the government should take measures, according to a study by I\&O Research (2019). When it comes to combating climate change, it appears that citizens are waiting for the government and businesses to lead by example (ibid.). Citizens believe having the government force businesses to adopt more sustainable production methods $(62 \%$ have high expectations) and encourage technological development by these businesses (63\%) will have the best effects. 6 out of 10 Dutch people (59\%) agree with the statement 'As long as big companies fail to cut their carbon emissions, what I do will not make a difference'. The government has therefore come to realize that it must take action in all possible areas, including standardization, charges, subsidies, legislative amendments, binding agreements, budgetary choices, and green deals between public and private parties to facilitate the transformation towards sustainability. Also the introduction of a carbon tax for polluting businesses, as part of the National Climate Agreement, is a good example of government intervention.

Every change in society will provoke resistance, and attempts to change established patterns always come up against resistance, rigidity, and/or normative questions as to the legitimacy, justness, methods, and direction of the transition (Grin 2016; Meadowcroft 2009). Society is usually stuck in its old structures, thought patterns, and vested interests. Good intentions often fail because of the discrepancy 
between long- and short-term interests. Front-runners may introduce valuable initiatives, but they can struggle to establish a level playing field in the market. In addition, laws and legislation often offer insufficient scope for experimentation.

As a result, many efforts in the sustainability transition are struggling to move beyond the initiation phase and fail to realize acceleration and consolidation (see Sect. 4.1). This stalling of a transition can be characterized as follows (cf. Foresight and Commonland 2017):

- 'Fragmentation: many small, competing initiatives and isolated projects'

- 'Narrow scope \& lack of holistic approach: progress is measured on short timespans, and relative to competitors; transformation approaches focus on optimizing only a few dimensions, potentially at the cost of others; projects focus on only one link in the system'

- 'Brittle: sustainability claims are based on marginal improvements'

- 'Focus on inputs and processes rather than on outcomes'

- 'Cause inflation: risk of losing credibility and being accused of greenwashing'.

The sustainability transition will also give rise to unease, discomfort, and uncertainty, both financial and otherwise, which means resistance is inevitable (RNE 2016). To fight this resistance to change, mitigate negative consequences, and compensate for the adverse effects of the transition, it is very important to offer citizens and businesses appealing short-term or long-term prospects or attractors. The circular economy, for instance, will require more raw material collection, recycling and upgrading, creating new, low-skilled jobs in the process (ibid.). Large-scale sustainable development of the built environment will also create new jobs in the construction and installation industry (ibid.).

The sustainability transition is characterized by significant complexity and uncertainty. The sustainable development of our cities, for instance, has become such a complex and dynamic issue that it can no longer be tackled by just one party alone, such as government, private sector, or civil society (Karré 2018). The transition to climate-proof cities, for instance, will raise normative questions on what will make cities climate-proof and who should bear the costs involved in the process (Eriksen et al. 2015). Complex social issues of this kind are characterized by incomplete or fragmented knowledge and differing interests, values and ideas about problems, causes, and solutions.

The transition to a sustainable society will only succeed if everyone is given the chance to participate and if the costs, benefits, and risks are all shared fairly and proportionally. However, sustainable lifestyles are often restricted to the more affluent layers of society. Grants intended to encourage sustainable behaviour often flow to people with higher incomes, who can afford to invest in solar panels and an electric car. One of the major risks of the sustainability transition, therefore, is overemphasizing individual responsibility and relying too little on structural, systemic, and collective solutions. A major pitfall with problems such as climate change or sustainable consumption is that it tends to be reduced to personal choices and responsibility. In reality, however, these are structural problems requiring structural solutions, such as regulations, policy, and financial measures. 
Besides an important role for government, it is clear that the sustainability transition can only succeed if all elements of society cooperate and assume their responsibilities. Sustainability certainly need not create a social divide between the 'green' and the 'grey' class, or between citizens and businesses, but should be part of an agenda for an inclusive society and social cohesion. A collective problem requires systemic, sustainable, and fair solutions, which requires all actors, including the government, the private sector, civil society, academia, and media to play their part.

\subsection{What's Beyond the Sustainable Development Goals?}

The term 'transition' or 'transformation' presupposes a fading to something new, a new state of mind, a new reality, a new normal, a new paradigm, or a new social contract. However, current literature on sustainability transitions is often occupied with the process, rather than its outputs, outcomes, or impacts (Köhler et al. 2019). This is illustrated by some transition scholars warning that describing the outcome can lead to processes in which the destination transcends the journey towards it (e.g. Haxeltine et al. 2016). Admittedly, precaution for trajectories where purpose justifies the means is undisputed, and requires careful attention for procedural justice (see Sect. 4.8). Moreover, dealing with complexity and uncertainty requires adaptive planning and governance (see Sect. 4.6), while a social learning process (see Sect. 4.7) is geared towards the process rather than a fixed goal (Bagheri and Hjorth 2007). This is something else, however, than developing a joint vision. A tangible and joint vision could serve as a vehicle to identify and develop shared and common values during the process of transformation. Agreement on these ethical and normative aspects is important for holding actor coalitions together during a transition process, and could be achieved through deliberation on shared beliefs and values, shared discourses, mutual understanding of common and diverging interests, procedural justice, and options for multiple value creation and mutual gains (see Sects. 3.8 and 4.8 in particular).

Within this context, literature on global environmental politics questions whether compliance with the Sustainable Development Goals should be considered as the ultimate goal of the sustainability transition, or whether we should be more explicit on what's beyond the 2030 Agenda (Wahl 2016; Dabelko and Conca 2019). Some scholars point out that the word sustainability itself is inadequate, as it does not tell us what we are actually trying to sustain (Wahl 2019). Wahl (2019) argues that design for sustainability is, ultimately, design for human and planetary health, which can be achieved through regenerative cultures (see Fig. 2.3).

Reicher and Hopkins (2001) argue 'that images of society's future are important for shaping social change. Social action must be animated by a vision of a future society, and by explicit judgements of value concerning the character of this future society' (cf. Chomsky 1970/1999, p100). A Natural Social Contract and the related concept of Transformative Social-Ecological Innovation, as proposed in this book (Chap. 3), serve as a vehicle to think about ways to improve current social contracts, targeting a sustainable, regenerative, healthy and just society, which can help 


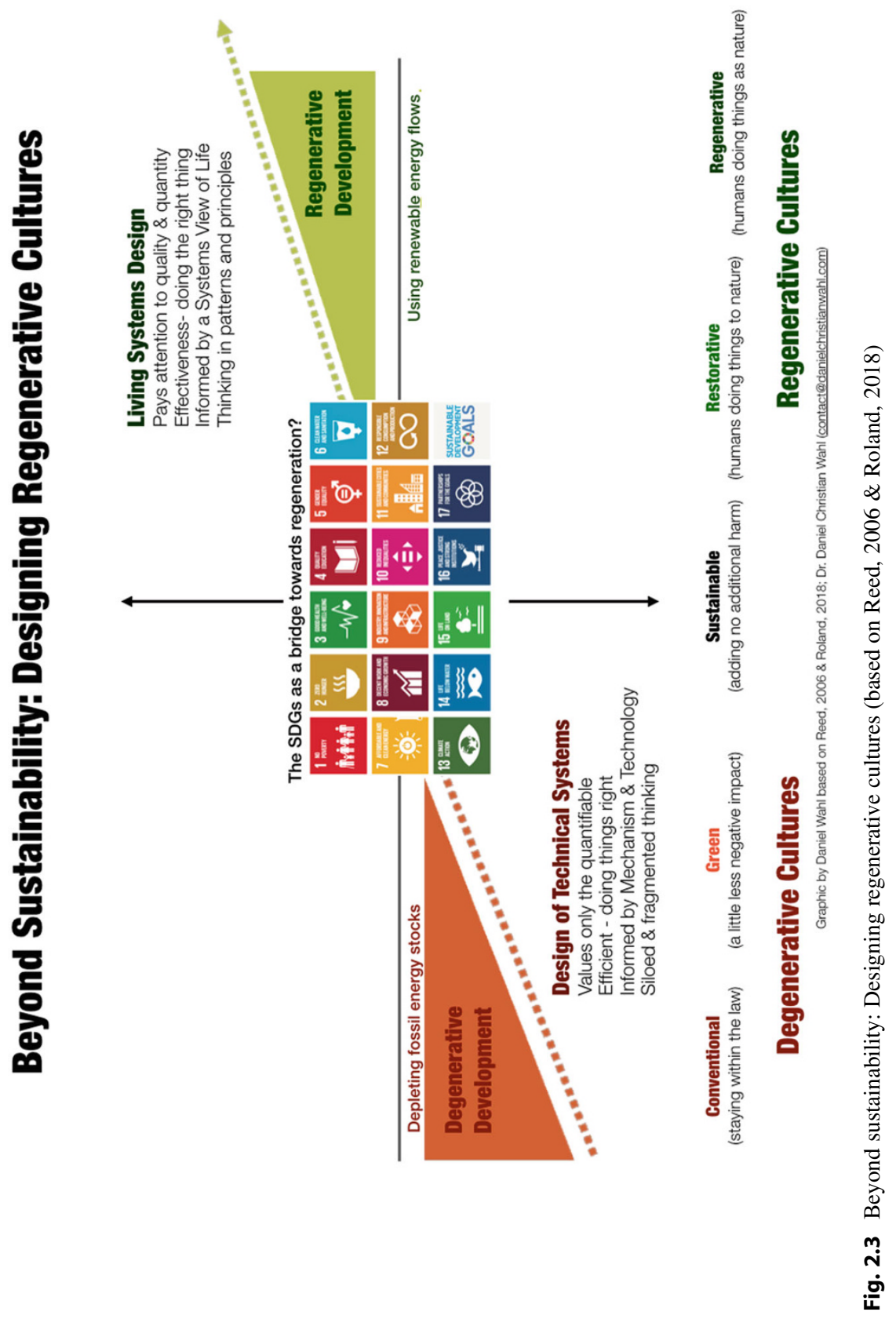


policymakers, administrators and decision makers, concerned citizens, and professionals to make better decisions about how to organize our twenty-firstcentury society. In further developing ideas about the future of society, research on how people think about their own future may offer useful insights (Bain et al. 2013).

Open Access This chapter is licensed under the terms of the Creative Commons Attribution 4.0 International License (http://creativecommons.org/licenses/by/4.0/), which permits use, sharing, adaptation, distribution and reproduction in any medium or format, as long as you give appropriate credit to the original author(s) and the source, provide a link to the Creative Commons license and indicate if changes were made.

The images or other third party material in this chapter are included in the chapter's Creative Commons license, unless indicated otherwise in a credit line to the material. If material is not included in the chapter's Creative Commons license and your intended use is not permitted by statutory regulation or exceeds the permitted use, you will need to obtain permission directly from the copyright holder.

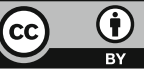

